\title{
Kinetic Models on Chromium (VI) Adsorption onto Carbonized Oil Palm Kernel with Potassium Hydroxide Activation
}

\author{
Panida Sampranpiboon ${ }^{1}$ and Xianshe Feng ${ }^{2}$
}

\begin{abstract}
Use of adsorption kinetic models for removal of chromium (VI) from aqueous solution by oil palm kernel with potassium hydroxide activation has been investigated. The adsorption capacity or amount of $\mathrm{Cr}(\mathrm{VI})$ adsorbed per unit mass of adsorbent was determined by the pseudo-zero order, pseudo-first order, pseudosecond order, intraparticle diffusion, Bangham pore diffusion, liquid film diffusion, modified Freundlich and Elovich models to describe the adsorption process. The kinetics data were marginally better fit with Elovich model as compared to other models. It is therefore suggest that the chemisorption was the rate controlling step for chromium (VI) adsorption onto the carbonized oil palm kernel with $\mathrm{KOH}$ activation as the adsorbent.
\end{abstract}

Keywords - chromium adsorption, kinetic model, oil palm kernel.

\section{INTRODUCTION}

The contamination of toxic heavy metal ions into the environment is a crucial problem to water quality. The water pollution is prevalent in majority countries and threatens the environment, the health of humans and wildlife. Chromium, one of the primary heavy metal pollutants, occurs in two stable oxidation states in aqueous solutions, $\mathrm{Cr}$ (III) and $\mathrm{Cr}$ (VI), and their properties are very different. Cr (III) has a limited hydroxide solubility and low toxicity. In contrast, $\mathrm{Cr}$ (VI), having mobile and strongly oxidant character, is known as mutagen and potential carcinogen. Common processes have been investigated for removing chromium from aqueous solutions. Principally, there are two types of treatment methods for $\mathrm{Cr}$ (VI) removal. One is to remove $\mathrm{Cr}$ (VI) directly, and the other is to reduce $\mathrm{Cr}$ (VI) to $\mathrm{Cr}$ (III).This is commonly considered due to its more impact on environment, owing to the reagents addition and cleaner produces with more settling production. The discharge limit of $\mathrm{Cr}$ (VI) into inland surface water is $0.1 \mathrm{ppm}$, and potable water is limited to $0.05 \mathrm{ppm}$. Most sources of water pollution with chromium are fertilizer, metal fabrication, electroplating plants, metal finishing, batteries, printing and mining. Due to the toxicity and nonbiocompatibility, various treatment methods are considered such as chemical precipitation, electroflotation, membrane processes and oxidation [1-3].

\footnotetext{
${ }^{1}$ Department of Chemical and Material Engineering, College of Engineering, Rangsit University, Pathumthani, 12000, Thailand

${ }^{2}$ Department of Chemical Engineering, College of Engineering, University of Waterloo, Ontario, N2L3G1, Canada
}

However, these techniques have certain disadvantages such as less efficiency, high treatment and disposal costs. Adsorption is considered to be a more efficient and costeffective technique for the removal of chromium from wastewater. Using suitable adsorbent to remove various toxic pollutants from industrial wastewater by adsorption is considered.

A review of $\mathrm{Cr}(\mathrm{VI})$ removal from aqueous solutions by raw and modified lignocellulosic materials [2-3] showed that oil palm waste has a few used as an adsorbent for Cr (VI) adsorption. Carbonized or activated carbon is produced from solid waste of palm oil processing mill (oil palm kernel or oil palm shell) in many tropical countries (e.g., India, Indonesia, Malaysia and Thailand). However, few facilities in Thailand produce adsorbents, and research is thus needed in order to obtain suitable product that meets to standards for environmental applications. As an initial part of the research, chemical activation using phosphoric acid $\left(\mathrm{H}_{3} \mathrm{PO}_{4}\right)$ and potassium hydroxide $(\mathrm{KOH})$ was employed to prepare carbonaceous materials as adsorbents from the oil palm kernel for $\mathrm{Cr}(\mathrm{VI})$ adsorption from aqueous solutions, and found that the potassium hydroxide was used to treat the oil palm kernel for carbonization at temperature $673 \mathrm{~K}$ for $2 \mathrm{~h}$, and showed a high surface area and $\mathrm{Cr}(\mathrm{VI})$ removal [1], and in this part of research, the kinetic adsorption models such as, the pseudozero order, pseudo-first order, pseudo-second order, intraparticle diffusion, Bangham pore diffusion, liquid film diffuse on, modified Freundlich and Elovich models were investigated to describe the adsorption process.

\section{MATERIAL AND METHODS}

The oil palm kernels were washed with distilled water and dried. Dried oil palm kernels were immersed in $1 \mathrm{~L}$ of $1 \mathrm{M}$ $\mathrm{KOH}$ for $1 \mathrm{~h}$, and filtered with a stainless screen before being carbonized in a Muffle furnace at $673 \mathrm{~K}$ for $2 \mathrm{~h}$, respectively. The carbonaceous material was cool and washed several times with hot water until $\mathrm{pH} 7$ and dried in oven to use as adsorbent for $\mathrm{Cr}$ (VI) adsorption. The final material was referred to as carbonized oil palm kernel with $\mathrm{KOH}$ activation (KOH-COP). The properties of surface area, pore volume and pore diameter $\mathrm{KOH}-\mathrm{MSP} \mathrm{C}$ are $164 \mathrm{~m} 2 / \mathrm{g}, 0.2411 \mathrm{cc} / \mathrm{g}$ and $58.81{ }^{\circ} \mathrm{A}$, respectively. Adsorption studies were conducted using a batch adsorption technique. A number of stoppered Duran glass Erlenmeyer containing $100 \mathrm{~mL}$ of chromium (VI) solution of at a desired concentration, $\mathrm{pH}$ and temperature was placed in a 
thermostatic shaker. In the studies, $1 \mathrm{~g}$ of the carbonaceous material was used to treat $100 \mathrm{~mL}$ of the $\mathrm{Cr}$ (VI) solution at a defined $\mathrm{pH}$ and temperature.

The flasks were agitated at a shaking rate of $110 \mathrm{rpm}$ for $2 \mathrm{~h}$ to ensure adsorption equilibrium. Samples were filtered with Whatman No.1 and No.42 filter papers and chromium (VI) content in the filtrate were analysed with an Atomic Adsorption Spectroscopy (model: Varian 640Z, 220). All experiments were carried out in duplicates and average values were reported.

\section{RESULTS AND DISCUSSION}

\section{A. Adsorption Study}

The impacts of changing the initial chromium (VI) concentration from 50 to $250 \mathrm{mg} / \mathrm{L}$, temperature from $303 \mathrm{~K}$ to $323 \mathrm{~K}$ were studied for $\mathrm{KOH}-\mathrm{COP}$ at a constant adsorbent dose $1 \mathrm{~g} / 100 \mathrm{~mL}$, pH 2.0, contact time 5, 10, 15, 30, 60, 120 min, stirring speed $110 \mathrm{rpm}$, on the chromium removal was obtained from the calculated with initial concentration and equilibrium concentration on the initial concentration as shown in Fig.1. When the initial $\mathrm{Cr}$ (VI) concentration in the solution increased from 50 to $100 \mathrm{ppm}$, the $\mathrm{Cr}$ (VI) removal increased. However, when the concentration increased from 100 to 250 ppm, the $\mathrm{Cr}(\mathrm{VI})$ removal decreased. Thus, the removal of $\mathrm{Cr}$ (VI) was dependent on the initial concentration. This is because at a low feed concentration, the ratio of available surface to the initial $\mathrm{Cr}(\mathrm{VI})$ concentration is high. However, in the case of higher concentrations, this ratio is low, and hence the percentage removal is also lower. The number of ions adsorbed from higher feed concentrations is more than that removed from less concentrated solutions. A higher metal concentration increased the mass transfer driving force, and thus increased the metal ions sorbed per unit weight of adsorbent at equilibrium. In addition, increasing metal ions and sorbent, which enhanced the sorption process. The same results were obtained with the temperature increased from 303 to 313 and $323 \mathrm{~K}$, respectively.

\section{B. Kinetic Adsorption Models}

The kinetic of $\mathrm{Cr}$ (VI) adsorption on KOH-COP, some adsorption kinetic models, namely, pseudo-zero order adsorption kinetic model [4], pseudo-first-order adsorption kinetic model [4], pseudo-second order adsorption kinetic model [4], intraparticle diffusion model [5], Bangham's pore diffusion model [6], liquid film diffusion kinetic model [7], modified Freundlich kinetic model [8] and Elovich model [9] are investigated to describe the adsorbate uptake.

The traditional methods of determining the kinetic adsorption parameters by linear regression appear to give a good fit to experimental data. However, the $\mathrm{R}^{2}$ is based on the linear forms of the kinetic equations, but does not represent the errors in the kinetic curves. To evaluate the fit of the kinetic equations to the experimental data, different error functions of non-linear regression were used here to determine the constants model parameters, and they were compared with those determined from the less accurate linearized data fitting. The residual root mean square error (RMSE) was used and defined as:
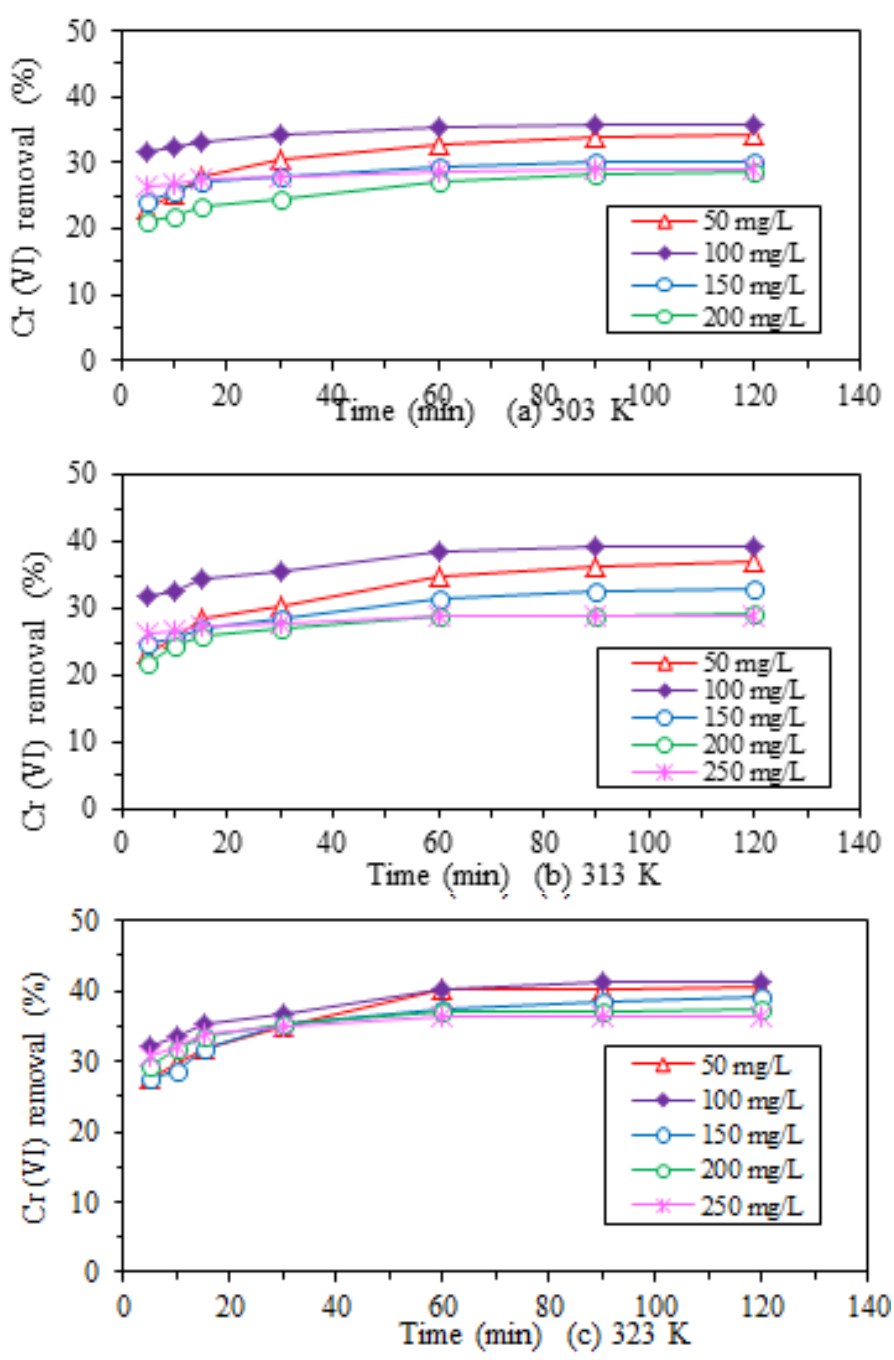

Fig.1: Effect of initial concentration 50, 100, 150, 200, $250 \mathrm{mg} / \mathrm{L}, \mathrm{pH}$ 2.0 on the $\mathrm{Cr}$ (IV) removal at temperature 303,313 and $323 \mathrm{~K}$

$$
\text { RMSE }=\sqrt{\frac{1}{n-2} \sum_{i=1}^{n}\left(q_{e, e x p}-q_{e, c a l}\right)^{2}}
$$

The subscripts "exp" and "cal" show the experimental and calculated values and $\mathrm{n}$ is the number of observations in the experimental data. The smaller the RMSE value, the better the curve fitting [10].

\section{B.1. Pseudo-Zero Order Adsorption Kinetic Model}

The chromium (VI) adsorption onto the $\mathrm{KOH}-\mathrm{COP}$, the adsorptions whose order is pseudo-zero are rare. The rate law of zero order is [4]:

$$
\begin{aligned}
\frac{\mathrm{dq}}{\mathrm{dt}} & =\mathrm{k}_{\mathrm{ad}, 0}\left[\mathrm{q}_{\mathrm{e}}-\mathrm{q}_{\mathrm{t}}\right]^{0} \\
& =\mathrm{k}_{\mathrm{ad}, 0}
\end{aligned}
$$


Where $\mathrm{q}_{\mathrm{t}}$, and $\mathrm{q}_{\mathrm{e}}$ are amounts of $\mathrm{Cr}(\mathrm{VI})$ adsorbed at time $\mathrm{t}$ and at equilibrium, respectively, and $\mathrm{k}_{\mathrm{ad}, \mathrm{o}}$ denote the adsorption rate constant. Thus, the rate of pseudo-zero order adsorption is a constant, independent of amounts of $\mathrm{Cr}$ (VI) adsorbed. Using the calculus with integration by applying the initial conditions $\mathrm{q}_{\mathrm{t}}=0$ at $\mathrm{t}=0$ and $\mathrm{q}_{\mathrm{t}}=\mathrm{q}_{\mathrm{e}}$ at $\mathrm{t}=\mathrm{t}$, it can be showed:

$$
\left(\mathrm{q}_{\mathrm{e}}-\mathrm{q}_{\mathrm{t}}\right)=\mathrm{q}_{\mathrm{e}}-\mathrm{k}_{\mathrm{ad}, 0} \mathrm{t}
$$

The adsorption rate constant, $\mathrm{k}_{\mathrm{ad}, 0}$ of zero-order adsorption can be calculated from the slope of linear plot of $\left(q_{e}-q_{t}\right)$ with t. Table 1 shows the adsorption kinetic parameters of pseudozero order adsorption kinetic model. It is observed that the correlation coefficients $\left(\mathrm{R}^{2}\right)$ were obtained from fit model moderately $\left(0.74 \leq \mathrm{R}^{2} \leq 0.91\right)$. This is because this model depends on only rate constant

TABLE I: Adsorption kinetic parameters of pseudo-zero order adsorption kinetic model

\begin{tabular}{|c|c|c|c|c|c|c|c|c|c|}
\hline \multirow{2}{*}{$\begin{array}{c}\text { Concentration } \\
(\mathrm{mg} / \mathrm{L})\end{array}$} & \multicolumn{3}{|c|}{$303 \mathrm{~K}$} & \multicolumn{2}{c|}{$313 \mathrm{~K}$} & \multicolumn{3}{c|}{$323 \mathrm{~K}$} \\
\cline { 2 - 9 } & $\mathrm{k}_{\mathrm{ad}, \mathrm{o}}$ & $\mathrm{R}^{2}$ & $\mathrm{RMSE}$ & $\mathrm{k}_{\mathrm{ad}, \mathrm{o}}$ & $\mathrm{R}^{2}$ & $\mathrm{RMSE}$ & $\mathrm{k}_{\mathrm{ad}, \mathrm{o}}$ & $\mathrm{R}^{2}$ & $\mathrm{RMSE}$ \\
\hline 50 & 0.0058 & 0.8162 & 0.7855 & 0.0073 & 0.8996 & 0.8070 & 0.0075 & 0.8798 & 0.6869 \\
100 & 0.0067 & 0.8645 & 2.2076 & 0.0085 & 0.9100 & 2.2320 & 0.0103 & 0.9132 & 0.9580 \\
150 & 0.0091 & 0.8500 & 2.5718 & 0.0140 & 0.9492 & 2.5750 & 0.0189 & 0.8344 & 1.9692 \\
200 & 0.0165 & 0.9313 & 2.9249 & 0.0141 & 0.7390 & 3.0965 & 0.0160 & 0.7483 & 1.6235 \\
250 & 0.0216 & 0.9125 & 3.4575 & 0.0072 & 0.7974 & 4.6037 & 0.0154 & 0.7728 & 1.5103 \\
\hline
\end{tabular}

B.2. Pseudo-first Order Adsorption Kinetic Model

A pseudo-first order adsorption is a adsorption whose rate depends on the amounts of $\mathrm{Cr}(\mathrm{VI})$ adsorption raised to the first power. The chemical rate is [4]:

$$
\ln \left(\mathrm{q}_{\mathrm{e}}-\mathrm{q}_{\mathrm{t}}\right)=\ln \mathrm{q}_{\mathrm{e}}-\mathrm{k}_{\mathrm{ad}, 1} \mathrm{t}
$$

After definite integration by applying the initial conditions $\mathrm{q}_{\mathrm{t}}=0$ at $\mathrm{t}=0$ and $\mathrm{q}_{\mathrm{t}}=\mathrm{q}_{\mathrm{e}}$ at $\mathrm{t}=\mathrm{t}$. The adsorption rate constant $\mathrm{k}_{\mathrm{ad}, 1}$ of pseudo-first order adsorption can be calculated from the plot of $\ln \left(\mathrm{q}_{\mathrm{e}}-\mathrm{q}_{\mathrm{t}}\right)$ against $\mathrm{t}$. Table 2 shows the adsorption kinetic data fit model well $\left(0.93 \leq \mathrm{R}^{2} \leq 0.95\right)$ and $\mathrm{RMSE}$ values are $0.6-4.98$.

TABLE II: Adsorption kinetic parameters of pseudo-first order adsorption kinetic model

\begin{tabular}{|c|l|c|l|c|c|c|c|c|c|}
\hline $\begin{array}{c}\text { Concentration } \\
(\mathrm{mg} / \mathrm{L})\end{array}$ & \multicolumn{3}{|c|}{$303 \mathrm{~K}$} & \multicolumn{2}{c|}{$313 \mathrm{~K}$} & \multicolumn{3}{c|}{$323 \mathrm{~K}$} \\
\cline { 2 - 10 } & $\mathrm{k}_{\mathrm{ad}, 1}$ & $\mathrm{R}^{2}$ & $\mathrm{RMSE}$ & $\mathrm{k}_{\mathrm{ad}, 1}$ & $\mathrm{R}^{2}$ & $\mathrm{RMSE}$ & $\mathrm{k}_{\mathrm{ad}, 1}$ & $\mathrm{R}^{2}$ & $\mathrm{RMSE}$ \\
\hline 50 & 0.0379 & 0.9960 & 0.7678 & 0.0384 & 0.9895 & 0.6981 & 0.0620 & 0.9329 & 0.7209 \\
100 & 0.0492 & 0.9955 & 2.1198 & 0.0428 & 0.9882 & 2.0566 & 0.0416 & 0.9896 & 2.0490 \\
150 & 0.0438 & 0.9786 & 2.4132 & 0.0373 & 0.9822 & 2.3044 & 0.0353 & 0.9920 & 2.7272 \\
200 & 0.0387 & 0.9775 & 2.6000 & 0.0415 & 0.9660 & 3.1118 & 0.0516 & 0.9748 & 4.0345 \\
250 & 0.0321 & 0.9360 & 3.1650 & 0.0424 & 0.9550 & 4.5802 & 0.0649 & 0.9867 & 4.9859 \\
\hline
\end{tabular}

\section{B.3. Pseudo-Second Order Adsorption Kinetic Model}

A pseudo-second order adsorption is a adsorption whose rate depends on the concentration of one reactant raised to the second power. Using calculus, we can obtain the following expressions for the second order adsorptions [4]:

$$
\frac{1}{\left(\mathrm{q}_{\mathrm{e}}-\mathrm{q}_{\mathrm{t}}\right)}=\frac{1}{\mathrm{q}_{\mathrm{e}}}+\mathrm{k}_{\mathrm{ad}} \mathrm{t}
$$

TABLE III: Adsorption kinetic parameters of pseudo-second order adsorption kinetic model

\begin{tabular}{|c|l|c|l|c|c|c|c|c|c|}
\hline \multirow{2}{*}{$\begin{array}{c}\text { Concentration } \\
(\mathrm{ppm})\end{array}$} & \multicolumn{3}{|c|}{$303 \mathrm{~K}$} & \multicolumn{2}{c|}{$313 \mathrm{~K}$} & \multicolumn{3}{c|}{$323 \mathrm{~K}$} \\
\cline { 2 - 10 } & $\mathrm{k}_{\mathrm{ad}, 2}$ & $\mathrm{R}^{2}$ & $\mathrm{RMSE}$ & $\mathrm{k}_{\mathrm{ad}, 2}$ & $\mathrm{R}^{2}$ & $\mathrm{RMSE}$ & $\mathrm{k}_{\mathrm{ad}, 2}$ & $\mathrm{R}^{2}$ & $\mathrm{RMSE}$ \\
\hline 50 & 0.5008 & 0.8774 & 0.4656 & 0.4279 & 0.8202 & 0.7175 & 2.1049 & 0.9395 & 0.7682 \\
100 & 1.5239 & 0.8388 & 0.5191 & 0.5220 & 0.8228 & 0.6686 & 0.3874 & 0.8323 & 1.1845 \\
150 & 0.5959 & 0.7619 & 1.4370 & 0.2073 & 0.8026 & 2.1179 & 0.1235 & 0.8793 & 3.2524 \\
200 & 0.2024 & 0.7856 & 2.7675 & 0.2604 & 0.9634 & 3.0757 & 0.5055 & 0.9400 & 4.4395 \\
250 & 0.0914 & 0.7537 & 3.9510 & 0.5283 & 0.9588 & 3.4225 & 1.5420 & 0.8301 & 5.4665 \\
\hline
\end{tabular}

\section{B.4. Intraparticle Diffusion Model}

The initial rate of intraparticle diffusion is calculated as follows [5]:

$$
\mathrm{q}_{\mathrm{t}}=\mathrm{k}_{\mathrm{id}} \mathrm{t}^{0.5}+\mathrm{C}
$$

Where $k_{\mathrm{id}}$ is intraparticle diffusion rate constant $(\mathrm{mg} / \mathrm{g}$ $\min ^{0.5}$ ) and obtained from the slope of linear plot of $\mathrm{q}_{\mathrm{t}}$ and $\mathrm{t}^{0.5}$. According to this model, the linear plot of $\mathrm{q}_{\mathrm{t}}$ and square root of time $\left(\mathrm{t}^{0.5}\right)$ should be linear if intraparticle diffusion is
The adsorption rate constant $\mathrm{k}_{\mathrm{ad}}$ of first order adsorption can be calculated from the slope of linear plot of $1 /\left(q_{e}-q_{t}\right)$ against t. Table 3 shows that the adsorption kinetic rate constants, $\mathrm{k}_{\mathrm{ad}, 2}$ were presented from fit model moderately and the correlation $0.75 \leq \mathrm{R}^{2} \leq 0.94$. 
TABLE IV: Adsorption kinetic parameters of intraparticle diffusion adsorption kinetic model

\begin{tabular}{|c|c|c|c|c|c|c|c|c|c|}
\hline $\begin{array}{c}\text { Concentration } \\
(\mathrm{mg} / \mathrm{L})\end{array}$ & \multicolumn{3}{|c|}{$303 \mathrm{~K}$} & \multicolumn{3}{c|}{$313 \mathrm{~K}$} & \multicolumn{3}{c|}{$323 \mathrm{~K}$} \\
\cline { 2 - 9 } & $\mathrm{k}_{\text {in }}$ & $\mathrm{R}^{2}$ & RMSE & $\mathrm{k}_{\mathrm{id}}$ & $\mathrm{R}^{2}$ & $\mathrm{RMSE}$ & $\mathrm{k}_{\mathrm{id}}$ & $\mathrm{R}^{2}$ & $\mathrm{RMSE}$ \\
\hline 50 & 0.3143 & 0.9485 & 1.7405 & 0.0793 & 0.9490 & 0.0558 & 0.0786 & 0.9155 & 0.0752 \\
100 & 0.2471 & 0.9591 & 1.3714 & 0.0907 & 0.9453 & 0.0680 & 0.1104 & 0.9494 & 0.0814 \\
150 & 0.4838 & 0.9582 & 2.6751 & 0.1518 & 0.9727 & 0.0915 & 0.2057 & 0.9116 & 0.1588 \\
200 & 0.8740 & 0.9839 & 4.7963 & 0.1512 & 0.8362 & 0.1486 & 0.1686 & 0.8339 & 0.1819 \\
250 & 1.1858 & 0.9778 & 6.4575 & 0.0766 & 0.8752 & 0.0719 & 0.1612 & 0.8468 & 0.1745 \\
\hline
\end{tabular}

\section{B.5. Bangham Pore Diffusion Model}

The Bangham equation is presented to limit by the pore diffusion at different adsorption time by following [6]:

$$
\log \log \left[\frac{C_{i}}{C_{i}-m q_{t}}\right]=\log \left[\frac{m K_{B}}{2.303 V}\right]+a_{B} \log t
$$

Where $\mathrm{m}$ is weight of adsorbent used in solution $(\mathrm{g} / \mathrm{L}) \mathrm{C}_{\mathrm{i}}$ is initial concentration of adsorbate in solution $(\mathrm{mg} / \mathrm{L}), \mathrm{a}_{\mathrm{B}}$ and $\mathrm{K}_{\mathrm{B}}$ constants were calculated from the intercept and slope of the linear plots of $\log \log \left[\mathrm{C}_{\mathrm{i}} /\left(\mathrm{C}_{\mathrm{i}}-\mathrm{mq}_{\mathrm{t}}\right]\right.$ against $\log \mathrm{t}$. This model can be used to check whether the pore diffusion is only ratecontrolling step or not. Table 5 shows that the most of adsorption kinetic data fit model well $\left(0.93 \leq \mathrm{R}^{2} \leq 0.95\right)$ and RMSE values are high in range 2-11. This may indicate that the diffusion of $\mathrm{Cr}(\mathrm{VI})$ into pores of the COP-KOH is not only rate controlling step.

TABLE V: Adsorption kinetic parameters of Bangham pore diffusion adsorption kinetic model

\begin{tabular}{|c|c|c|c|c|c|c|c|c|c|c|c|c|}
\hline $\begin{array}{c}\text { Concentration } \\
(\mathrm{mg} / \mathrm{L})\end{array}$ & \multicolumn{4}{|c|}{$303 \mathrm{~K}$} & \multicolumn{4}{c|}{$313 \mathrm{~K}$} & \multicolumn{4}{|c|}{$323 \mathrm{~K}$} \\
\cline { 2 - 14 } & $\mathrm{k}_{\mathrm{b}}$ & $\mathrm{a}_{\mathrm{b}}$ & $\mathrm{R}^{2}$ & RMSE & $\mathrm{k}_{\mathrm{b}}$ & $\mathrm{a}_{\mathrm{b}}$ & $\mathrm{R}^{2}$ & RMSE & $\mathrm{k}_{\mathrm{b}}$ & $\mathrm{a}_{\mathrm{b}}$ & $\mathrm{R}^{2}$ & RMSE \\
\hline 50 & 2.0790 & 0.1538 & 0.9721 & 2.3271 & 1.9819 & 0.1821 & 0.9886 & 2.2302 & 2.4590 & 0.1648 & 0.9716 & 2.1058 \\
100 & 3.4742 & 0.0530 & 0.9815 & 4.5446 & 3.2871 & 0.0909 & 0.9758 & 4.2829 & 3.2283 & 0.1083 & 0.9814 & 4.1451 \\
150 & 2.4706 & 0.0813 & 0.9805 & 7.4091 & 2.2990 & 0.1176 & 0.9828 & 7.1043 & 2.5109 & 0.1478 & 0.9684 & 6.4630 \\
200 & 1.9205 & 0.1183 & 0.9860 & 10.1208 & 2.1785 & 0.1024 & 0.9376 & 10.0247 & 3.0899 & 0.0928 & 0.9433 & 8.8749 \\
250 & 1.7787 & 0.1314 & 0.9766 & 12.6657 & 2.8664 & 0.0385 & 0.9604 & 12.5684 & 3.3239 & 0.0703 & 0.9502 & 11.2267 \\
\hline
\end{tabular}

B.6. Liquid Film Diffusion Kinetic Model

The liquid film diffusion equation is presented by following [7]:

$$
\begin{aligned}
& \ln \left(1-\frac{\mathrm{q}_{\mathrm{t}}}{\mathrm{q}_{\mathrm{e}}}\right)=-\mathrm{K}_{\mathrm{lf}} \mathrm{t} \\
& \mathrm{q}_{\mathrm{t}}=\mathrm{q}_{\mathrm{e}}-\mathrm{q}_{\mathrm{e}} \mathrm{e}^{-\mathrm{k}_{1 \mathrm{f}} \mathrm{t}}
\end{aligned}
$$

Where $\mathrm{k}_{\mathrm{lf}}$ is the external mass transfer coefficient $(1 / \mathrm{min})$.
The linear plot of $\ln \left(1-\mathrm{q}_{\mathrm{t}} / \mathrm{q}_{\mathrm{e}}\right)$ against $\mathrm{t}$, the zero intercept may expect that the adsorption process is controlled by diffusion through the liquid film surrounding the solid adsorbent. $\mathrm{k}_{\mathrm{lf}}$ can be calculated from the slope of plot of $\mathrm{q}_{\mathrm{t}}$ against $e^{-t}$. Table 6 shows the external mass transfer coefficients obtained from the plot of $\mathrm{q}_{\mathrm{t}}$ against $\mathrm{e}^{-\mathrm{t}}, \mathrm{k}_{\mathrm{lf}}$. The experimental data have given the poor correlations $\left(\mathrm{R}^{2}<0.6\right)$, this is confirmed that the kinetic of adsorption process is not controlled by diffusion through the liquid film surrounding the solid adsorbent.

TABLE VI: Adsorption kinetic parameters of liquid film diffusion adsorption kinetic model

\begin{tabular}{|c|c|c|c|c|c|c|c|c|c|}
\hline \multirow{2}{*}{$\begin{array}{c}\text { Concentration } \\
(\mathrm{mg} / \mathrm{L})\end{array}$} & \multicolumn{3}{|c|}{$303 \mathrm{~K}$} & \multicolumn{3}{|c|}{$313 \mathrm{~K}$} & \multicolumn{2}{c|}{$323 \mathrm{~K}$} \\
\cline { 2 - 9 } & $\mathrm{k}_{\mathrm{fd}}$ & $\mathrm{R}^{2}$ & $\mathrm{RMSE}$ & $\mathrm{k}_{\mathrm{fd}}$ & $\mathrm{R}^{2}$ & $\mathrm{RMSE}$ & $\mathrm{k}_{\mathrm{fd}}$ & $\mathrm{R}^{2}$ & $\mathrm{RMSE}$ \\
\hline 50 & 3.6515 & 0.4619 & 1.0870 & 3.7254 & 0.3905 & 1.1363 & 3.5714 & 0.3589 & 1.2813 \\
100 & 2.5281 & 0.3999 & 2.4317 & 2.9549 & 0.3324 & 2.5952 & 3.1340 & 0.3470 & 2.6911 \\
150 & 3.0655 & 0.4666 & 3.0064 & 3.2213 & 0.3070 & 3.1529 & 3.4750 & 0.3620 & 3.7177 \\
200 & 3.3019 & 0.3420 & 3.6223 & 3.4182 & 0.5929 & 3.8650 & 3.2213 & 0.5358 & 4.9957 \\
250 & 3.4136 & 0.3439 & 4.4213 & 2.3137 & 0.4386 & 4.9683 & 2.9320 & 0.5118 & 6.1884 \\
\hline
\end{tabular}

\section{B.7. Modified Freundlich Kinetic Model}

The modified Freundlich equation is expressed by the following [8]:

$$
\begin{aligned}
\mathrm{q}_{\mathrm{t}} & =\mathrm{K}_{\mathrm{mf}} \mathrm{C}_{\mathrm{i}} \mathrm{t}^{1 / \mathrm{m}_{\mathrm{mf}}} \\
\ln \mathrm{q}_{\mathrm{t}} & =\ln \left[\mathrm{K}_{\mathrm{mf}} \mathrm{C}_{\mathrm{i}}\right]+\frac{1}{\mathrm{~m}_{\mathrm{mf}}} \ln \mathrm{t}
\end{aligned}
$$

where $\mathrm{k}_{\mathrm{mf}}$ is the apparent adsorption rate constant $(\mathrm{L} / \mathrm{g}$ $\min ), \mathrm{m}_{\mathrm{mf}}$ is a constant, $\mathrm{Ci}$ is the initial $\mathrm{Cr}(\mathrm{VI})$ concentration $(\mathrm{mg} / \mathrm{L})$. The values of $\mathrm{k}_{\mathrm{mf}}$ and $\mathrm{m}_{\mathrm{mf}}$ are used empirically to evaluate the effect of surface loading and ionic strength on the adsorption process and also can be obtained from intercept and slope of linear of $\ln \mathrm{q}_{\mathrm{t}}$ and $\ln \mathrm{t}$, respectively. From the results, the modified Freundlich model fit the experimental data well, according to $\mathrm{R}^{2}$ values listed in Table $7\left(0.93 \leq \mathrm{R}^{2} \leq 0.98\right)$. The RMSE values are between $0.04-0.14$. 
TABLE VII: Adsorption kinetic parameters of modified Freundlich adsorption kinetic model

\begin{tabular}{|c|c|c|c|c|c|c|c|c|c|c|c|c|}
\hline \multirow{2}{*}{$\begin{array}{c}\text { Concentration } \\
(\mathrm{mg} / \mathrm{L})\end{array}$} & \multicolumn{4}{|c|}{$303 \mathrm{~K}$} & \multicolumn{4}{|c|}{$313 \mathrm{~K}$} & \multicolumn{4}{|c|}{$323 \mathrm{~K}$} \\
\hline & $\mathrm{k}_{\mathrm{mf}}$ & $\mathrm{m}_{\mathrm{mf}}$ & $\mathrm{R}^{2}$ & RMSE & $\mathrm{k}_{\mathrm{mf}}$ & $\mathrm{m}_{\mathrm{mf}}$ & $\mathrm{R}^{2}$ & RMSE & $\mathrm{k}_{\mathrm{mf}}$ & $\mathrm{m}_{\mathrm{mf}}$ & $\mathrm{R}^{2}$ & RMSE \\
\hline 50 & 0.0190 & 7.7364 & 0.9690 & 0.0400 & 0.0203 & 6.6084 & 0.9875 & 0.0332 & 0.0222 & 7.5445 & 0.9720 & 0.0523 \\
\hline 100 & 0.0294 & 23.3566 & 0.9813 & 0.0260 & 0.0282 & 13.8489 & 0.9762 & 0.0296 & 0.0279 & 11.7303 & 0.9819 & 0.0367 \\
\hline 150 & 0.0220 & 14.4897 & 0.9794 & 0.0454 & 0.0207 & 10.1262 & 0.9838 & 0.0244 & 0.0225 & 8.3361 & 0.9660 & 0.1011 \\
\hline 200 & 0.0176 & 9.7792 & 0.9864 & 0.0409 & 0.0197 & 11.3747 & 0.9342 & 0.1203 & 0.0267 & 13.3328 & 0.9403 & 0.1455 \\
\hline 250 & 0.0164 & 8.7590 & 0.9767 & 0.0079 & 0.0249 & 30.6816 & 0.9599 & 0.0445 & 0.0284 & 17.6163 & 0.9483 & 0.1306 \\
\hline
\end{tabular}

\section{B.8. Elovich Adsorption Kinetic Model}

Elovich equation is presented to describe the actual adsorbent surfaces are energetically heterogeneous by the following Aroua et. al [9]. This reaction also involves chemisorption of the adsorbate on a solid surface without desorption. The adsorption rate decreases with time due to and increased surface coverage. The mechanism of adsorbent and adsorbate does not consider in the equation (10).

$$
\mathrm{q}_{\mathrm{t}}=\frac{1}{\mathrm{~B}} \ln \mathrm{AB}-\frac{1}{\mathrm{~B}} \ln \mathrm{t}
$$

Where $\mathrm{A}$ is the initial adsorption rate ( $\mathrm{mg} / \mathrm{g} \mathrm{min})$ and $\mathrm{B}$ is related to extent of surface coverage and activation energy for chemisorption $(\mathrm{g} / \mathrm{mg})$ and calculated from the intercept and slope of the plots $\mathrm{q}_{\mathrm{t}}$ and $\ln \mathrm{t}$. Table 8 shows the adsorption kinetic parameters of Elovich adsorption kinetic model. It is observed that the adsorption kinetic data fit model very well $\left(\mathrm{R}^{2}>0.95\right)$ and RMSE values are 0.4-0.6.

TABLE VIII: Adsorption kinetic parameters of Elovich adsorption kinetic model

\begin{tabular}{|c|c|c|c|c|c|c|c|c|c|c|c|c|}
\hline \multirow{2}{*}{$\begin{array}{c}\text { Concentration } \\
(\mathrm{mg} / \mathrm{L})\end{array}$} & \multicolumn{4}{|c|}{$303 \mathrm{~K}$} & \multicolumn{4}{|c|}{$313 \mathrm{~K}$} & \multicolumn{4}{|c|}{$323 \mathrm{~K}$} \\
\hline & A & B & $\mathrm{R}^{2}$ & RMSE & A & B & $\mathrm{R}^{2}$ & RMSE & A & $\mathrm{B}$ & $\mathrm{R}^{2}$ & RMSE \\
\hline 50 & $5.75 \times 10^{2}$ & 5.4128 & 0.9818 & 0.4679 & $1.39 \times 10^{2}$ & 4.4048 & 0.9893 & 0.4932 & $3.52 \times 10^{2}$ & 4.4141 & 0.9690 & 0.5144 \\
\hline 100 & $3.99 \times 10^{9}$ & 6.9224 & 0.9821 & 0.4184 & $1.57 \times 10^{5}$ & 3.8740 & 0.9744 & 0.5168 & $1.57 \times 10^{4}$ & 3.1829 & 0.9795 & 0.5405 \\
\hline 150 & $3.01 \times 10^{5}$ & 3.5299 & 0.9842 & 0.5410 & $2.22 \times 10^{3}$ & 2.3439 & 0.9779 & 0.5237 & $3.06 \times 10^{2}$ & 1.6784 & 0.9736 & 0.5024 \\
\hline 200 & $1.37 \times 10^{3}$ & 1.9817 & 0.9827 & 0.5091 & $9.73 \times 10^{3}$ & 2.2119 & 0.9517 & 0.6025 & $5.99 \times 10^{4}$ & 1.9816 & 0.9509 & 0.6106 \\
\hline 250 & $3.69 \times 10^{2}$ & 1.4623 & 0.9742 & 0.3450 & $4.12 \times 10^{12}$ & 4.4412 & 0.9625 & 0.5155 & $4.39 \times 10^{6}$ & 2.0837 & 0.9550 & 0.6133 \\
\hline
\end{tabular}

Since the pseudo-zero order, pseudo-first order and pseudosecond order adsorption kinetic models concerned with speed, or rates, at which a chemical reaction occurs. The kinetic is the movement or change in concentration of reactant or product with time; therefore, kinetic refers to the rate of the reaction, or the reaction rate and could not identify the diffusion mechanism; the kinetic results have to analyze by using intraparticle diffusion model, Bangham pore diffusion and liquid film diffusion kinetic models. The modified Freundlich model has been used to analyze about the effect of temperature to nature of the adsorption process. The Elovich model is involved the chemisorption of the adsorbate on a solid surface without desorption of product, adsorption rate decreased with time due to an increased surface coverage.

Several kinetic models have been used to predict the variation of adsorbed Cr (VI) with time. The RMSE and the kinetic parameters are given in Table 1 - Table 8 to representation that the Elovich adsorption model has the high $\mathrm{R}^{2}$ for all condition and RMSE value has very low. When the initial $\mathrm{Cr}$ (VI) concentration increased from $50 \mathrm{mg} / \mathrm{L}$ to $100 \mathrm{mg} / \mathrm{L}$ to A higher, the adsorption rate increased, when concentration increased from $100-250 \mathrm{mg} / \mathrm{L}$, the adsorption rate decreased to A lower, according to the $\mathrm{Cr}$ (VI) removal for at temperatures $303 \mathrm{~K}, 313 \mathrm{~K}$ and $323 \mathrm{~K}$, respectively.

\section{CONCLUSION}

The kinetics data were marginally better fit with Elovich model as compared to other models. It is therefore suggest that the chemisorption was the rate controlling step for chromium (VI) adsorption onto the $\mathrm{KOH}-\mathrm{COP}$.

\section{REFERENCES}

[1] P. Sampranpiboon, and X. Feng, "Use of Phosphoric Acid and Sodium Hydroxide to Treat Carbonization Products of Oil Palm Kernel for Chromium (VI) Removal", in Proc. The 4th TIChE International Conference 2014, pp. 1-7.

[2] A.Demirbas, "Heavy Metal Adsorption onto Agro-based Waste Materials: A Review", Journal of Hazardous Material, vol.157, pp. 220-229, 2008.

http://dx.doi.org/10.1016/j.jhazmat.2008.01.024

[3] F. Fu, and Q.Wang, "Removal of heavy metal ions from wastewaters: A review", Journal of Environment Management, vol. 92, pp.407-418, 2011.

http://dx.doi.org/10.1016/j.jenvman.2010.11.011

[4] P. Sampranpiboon, and P.Charnkeitkong, "Equilibrium Isotherm, Thermodynamic and Kinetic Studies of Lead adsorption onto pineapple and paper waste sludges", International of Energy and Enviroment, vol. 4, pp. $88-98,201$.

[5] G.Varak, A. Demir, K. Yetimezsoy, S. Top, E. Sekman and M.S. Bilgili, "Removal of 4-nitrophenol from aqueous solution by natural low-cost adsorpbents", Indain Journal of Chemical Technology, vol.12, pp. 7-25, 2012.

[6] M. Suneetha, B.S. Sundar, K. Ravindhranath, "Removal of fluoride from polluted waters using active carbon derived from barks of Vitex negundo plant", Journal of Analytical Science and Technology, vol.6, pp. 1-15, 2015. http://dx.doi.org/10.1186/s40543-014-0042-1

[7] S.S. Gupta and K.G. Bhattacharyya, "Adsorption of Ni(II) on clay", Journal of Colloid and Interface Science, vol.295, pp.21-32, 2006. http://dx.doi.org/10.1016/j.jcis.2005.07.073

[8] K. Vijayaraghavan, T.V.N. Pramed, K. Palanivelu,M. Velan, "Biosorption of nickel(II) ions onto Sargassum wightii: Application of two-parameter and three-parameter isotherm models", Journal of Hazardous Material, vol.133, pp. 304-308, 2006. http://dx.doi.org/10.1016/j.jhazmat.2005.10.016

[9] M.K. Aroua, S. P. Leong, P. Teo, C. Y. Yin, W.M.A.W. Daud, "Realtime determination of kinetics of adsorption of lead(II) onto palm shellbased activated carbon using ion selective electrode", Bioresource Technology, vol.99, pp. 5786-5792, 2008.

http://dx.doi.org/10.1016/j.biortech.2007.10.010 
Int'l Journal of Advances in Chemical Engg., \& Biological Sciences (IJACEBS) Vol. 3, Issue 1 (2016) ISSN 2349-1507 EISSN 2349-1515

[10] S. Chowdhury, P. Saha, Adsorption thermodynamics and kinetics of Malachite Green onto $\mathrm{Ca}(\mathrm{OH}) 2$-treated fly ash, Journal of Environmental Engineering, Vol. 137, pp. 388-397, 2011. http://dx.doi.org/10.1061/(ASCE)EE.1943-7870.0000334 